\title{
Distracting the self: shifting attention prevents ego depletion
}

Citation for published version (APA):

Alberts, H. J. E. M., Martijn, C., Nievelstein, F., Jansen, A. T. M., \& de Vries, N. K. (2008). Distracting the self: shifting attention prevents ego depletion. Self and Identity, 7, 322-334.

https://doi.org/10.1080/15298860801987583

Document status and date:

Published: 01/01/2008

DOI:

10.1080/15298860801987583

Document Version:

Publisher's PDF, also known as Version of record

Document license:

Taverne

Please check the document version of this publication:

- A submitted manuscript is the version of the article upon submission and before peer-review. There can be important differences between the submitted version and the official published version of record.

People interested in the research are advised to contact the author for the final version of the publication, or visit the DOI to the publisher's website.

- The final author version and the galley proof are versions of the publication after peer review.

- The final published version features the final layout of the paper including the volume, issue and page numbers.

Link to publication

\footnotetext{
General rights rights.

- You may freely distribute the URL identifying the publication in the public portal. please follow below link for the End User Agreement:

www.umlib.nl/taverne-license

Take down policy

If you believe that this document breaches copyright please contact us at:

repository@maastrichtuniversity.nl

providing details and we will investigate your claim.
}

Copyright and moral rights for the publications made accessible in the public portal are retained by the authors and/or other copyright owners and it is a condition of accessing publications that users recognise and abide by the legal requirements associated with these

- Users may download and print one copy of any publication from the public portal for the purpose of private study or research.

- You may not further distribute the material or use it for any profit-making activity or commercial gain

If the publication is distributed under the terms of Article $25 \mathrm{fa}$ of the Dutch Copyright Act, indicated by the "Taverne" license above, 


\section{Distracting the Self: Shifting Attention Prevents Ego Depletion}

Hugo J. E. M. Alberts , Carolien Martijn , Fleurie Nievelstein , Anita Jansen \& Nanne K. de Vries

To cite this article: Hugo J. E. M. Alberts, Carolien Martijn , Fleurie Nievelstein , Anita Jansen \& Nanne K. de Vries (2008) Distracting the Self: Shifting Attention Prevents Ego Depletion, Self and Identity, 7:3, 322-334, DOI: 10.1080/15298860801987583

To link to this article: https://doi.org/10.1080/15298860801987583

册Published online: 12 Jun 2008.

Submit your article to this journal $₫$

Llll Article views: 588

Q View related articles $\sqsubset$

4 Citing articles: 4 View citing articles 지 


\title{
Distracting the Self: Shifting Attention Prevents Ego Depletion
}

\author{
HUGO J. E. M. ALBERTS \\ CAROLIEN MARTIJN \\ FLEURIE NIEVELSTEIN \\ ANITA JANSEN \\ NANNE K. DE VRIES
}

Universiteit Maastricht, Maastricht, The Netherlands

\begin{abstract}
The present research tested predictions of the strength model of self-control and delay of gratification by examining the effects of initial self-control attempts and also attention on performance. Participants completed a series of two identical physical self-control tasks, namely holding up a weight, under varying conditions. The results showed that performance decrements can be overcome by attentional strategies. When participants distracted themselves by performing a calculation task during the second self-control measurement, they did not show a decline in performance. In contrast, participants who did not distract themselves and those who instead focused on their muscles while holding up the weight, performed significantly worse on the second measurement. Interestingly, the distraction task reduced regulatory performance when it was performed before the second measurement.
\end{abstract}

Keywords: Self-control; Attention; Ego depletion; Distraction; Self-regulation.

Controlling oneself is often difficult: attempts to quit smoking are accompanied by withdrawal symptoms and intense craving, physical exercise is tiresome and may even hurt, and it can be immensely effortful to stay friendly to a blunt colleague or to a difficult teenage daughter. What strategies may people employ to help them to control themselves successfully in order to reach their longer term goals?

In this paper, we concentrate on the role of initial control exertion and attention on self-control performance - to contrast the predictions of the limited strength model of self-control (Muraven \& Baumeister, 2000; Muraven, Tice, \& Baumeister, 1998) and delay of gratification (Mischel \& Ebbesen, 1970).

Received 27 September 2006; accepted 11 February 2008; first published online 24 May 2008.

This work was supported by a grant of the Netherlands Organization for Scientific Research (NWO, Grant No. NWO, Grant No. 402-01-049).

Fleurie E. R. M. Nievelstein is now at the Educational Technology Expertise Centre, Open Universiteit Nederland, Heerlen, The Netherlands.

Correspondence should be addressed to: Hugo Alberts, Faculty of Psychology, Department of Clinical Psychological Science, Universiteit Maastricht, PO Box 616, NL-6200 MD Maastricht, The Netherlands. E-mail: h.alberts@psychology.unimaas.nl 


\section{Delay of Gratification}

Previous research on attention and effective self-control has mainly emphasized the benefits of focusing attention away from the self-control-demanding action. For instance, in their delay of gratification paradigm, Mischel and Ebbesen (1970) exposed children to the dilemma of choosing between an immediate small treat or a delayed larger reward. An important observation in these studies was that some children were noticeably better able to delay gratification than others. It appeared that the success of these children was due to the usage of attentional strategies: they were able to shift their attention to other objects in the room, or dissociated themselves by focusing on the abstract properties of desired stimuli-thinking about sweets as little clouds, or imagining that they were just a picture and not real (see also Rodrigues, Mischel, \& Shoda, 1989). In a later study on delay of gratification by Mischel, Ebbesen, and Zeiss (1972), the impact of attentional strategies was tested by externally supplying (instead of observing) the use of attentional strategies. These studies consistently showed that when children were given attentional strategies that helped to focus attention away from the selfcontrol-demanding action, they were able to inhibit their wanting of an immediate reward and wait significantly longer.

The findings of the above described studies suggest that self-control performance increases when attention is directed away from the unpleasant sensations generated by the self-control task. We assume that these unpleasant sensations involve awareness of needing to resist the urge to quit the self-control effort and will therefore from now on refer to them as "resistance-related sensations". This may imply that the awareness of resistance-related sensations during self-control contributes to self-control failure. Past research findings indeed support this rationale. For instance, in a delay of gratification study by Yates and Revelle (1979), the immediate and delayed rewards were either exposed or concealed. The results showed that having rewards available for attention dramatically reduced children's ability to wait. Likewise, Karniol and Miller (1983) found that the more people think about the instant pleasure associated with immediate stimuli that trigger impulses to engage in a behavior, the harder it becomes to resist it.

In order to explain the processes that underlie the findings of the above described studies using the delay of gratification paradigm, Metcalfe and Mischel (1999) proposed a neural network model in which self-control occurs through an interaction between a hot, affective, "go" system and a cool, cognitive, "know" system. While the hot system develops early and is under stimulus control, the cool system develops later and is under self-control. According to the model, focusing attention away from the self-control-demanding action can best be understood in terms of directing attention away from hot reward properties of a stimulus. Less attention to the self-control action leads to less input for the hot system, and thus to less influence of this system on behavior. The result is a facilitation of self-control. In contrast, focusing attention on the self-control action is expected to direct attention toward hot reward properties of a stimulus, thereby increasing input for the hot system. As a consequence, the likelihood of a go reaction will be increased and selfcontrol is more likely to fail (see also Strack \& Deutsch, 2004). Note, however, that it is not the hot reward properties of a stimulus as they are that cause self-control failure. It is the fact that these hot properties need to be resisted that makes selfcontrol so demanding. 


\section{The Limited Strength Model}

According to the limited strength model (Muraven \& Baumeister, 2000; Muraven et al., 1998), self-control draws on a general source of energy. After an act of selfcontrol, the resource becomes depleted and an individual finds him- or herself in a state of ego depletion. Consequently, a second act of self-control results in impaired performance. The literature on ego depletion identifies a number of features of the energy resource. First, the resource is non-specific and is used for a broad variety of self-control operations such as overriding or inhibiting impulses, thought suppression, regulating emotions, making choices, and so on. Second, the resource is limited, that is, the energy spent on resisting a fattening snack is no longer available to suppress a negative emotion. Third, self-control operates like a muscle. Like a muscle, self-control becomes tired after use and needs rest and relaxation to recover.

By now, the phenomenon of ego depletion is a well-researched phenomenon and empirical tests have shown that self-regulatory resources underlie a wide range of behaviors. Examples of findings are that the regulation of thoughts (i.e., suppressing a specific thought), altering one's emotional state (i.e., suppressing or exaggerating happy or sad emotions), and decision making involve self-control and that each of these activities results in impaired performance on a second self-control activity (see Schmeichel \& Baumeister, 2004, for an overview).

For instance, in a study by Muraven et al. (1998), participants were depleted by means of a thought-suppression task. Participants were instructed to write down all their thoughts on paper and were told to try not to think about a white bear. Control participants were given no thought suppression instruction. Next, all participants took part in a "problem-solving task" that consisted of a series of anagrams. Participants were not aware that these anagrams were in fact unsolvable and that the time they spent on this frustrating task served as a measure of their self-control. The exertion of self-control, that is, suppressing thoughts about a white bear, was found to undermine subsequent persistence with unsolvable anagrams. Participants who were instructed to regulate their thoughts spent less time and made less attempts to solve the anagrams than participants who did not receive this instruction. Thus, initial exercise of self-control hampered participants' behavior on a second, unrelated, self-control task.

Although a growing number of studies indeed prove impaired performance after self-control, other findings reveal that this decline in performance does not always occur. For instance, Muraven and Slessarava (2003) conducted a series of experiments in which they showed that ego depletion may be compensated for by increasing people's motivation to perform well on a subsequent self-control task. In one of their experiments, motivation was manipulated by informing participants that their performance on a second self-control task would benefit the treatment of Alzheimer patients. Initially depleted participants who received this information persisted longer on the subsequent self-control task than depleted participants who did not receive this information.

In addition, a recent study by Alberts, Martijn, Greb, Merckelbach, and de Vries (2007), demonstrated that this positive effect on self-control performance could also be induced by manipulations that do not require conscious awareness. Two experiments were conducted in which different priming procedures were used to activate the behavioral concept of persistence. Depleted participants who were primed with persistence performed significantly better on a subsequent self-control task than depleted participants who were exposed to a neutral prime. Priming of 
persistence caused initially depleted participants to overcome ego depletion: no decline in performance was found. In contrast, depleted participants who were exposed to a neutral prime displayed the standard ego depletion effect. In sum, the above described experiments illustrate that the occurrence of ego depletion is not inevitable. Likewise, in the current experiment we anticipated that employment of attentional strategies might help to circumvent the negative effects of ego depletion. More specifically, we predicted that directing attention away from resistance-related sensations would increase regulatory performance. In contrast, a focus on the selfcontrol inhibiting sensations was expected to reduce performance. In other words, an excessive focus might lead to stronger depletion effects.

In a recent series of experiments by Schmeichel (2007), it was demonstrated that initial efforts at executive control (e.g., attention control, response inhibition and memory updating) require cognitive resources and temporarily decrease performance on later tasks that require executive control. In one of these experiments, it was found that performance on an initial memory updating task resulted in decreased performance on a subsequent self-control task that required participants to inhibit their emotions (Schmeichel, 2007, Experiment 3). This is relevant because in the present work we also used a memory updating task in order to test the hypothesis that performing a task that requires cognitive resources prior to a self-control attempt has the same impact on regulatory performance as when using this task as a distraction, namely by performing the task during a self-control attempt.

\section{The Present Study}

The purpose of the present study was to examine the influence of attentional control strategies on self-control performance. Our reasoning was based on evidence from past research, namely that the awareness of unpleasant, resistance-related sensations (refusing to give in to "hot" reward stimulus properties) during self-control is an important factor contributing to self-control failure (Karniol \& Miller, 1983; Yates $\&$ Revelle, 1979). In the current study we aimed to test this rationale more directly. In doing so, we differentiated between attention that is directed toward versus away from the unpleasant sensations during a self-control operation. Past research findings using the delay of gratification paradigm have demonstrated that when children focus attention away from the self-control task and its unpleasantness by distracting themselves regulatory performance improves.

The present research aimed to extend these findings. First, unlike past studies on attention focus and self-control in which participants were mainly children, the current experiment involved adult participants. Second, the delay of gratification paradigm entails a more passive form of self-control, namely waiting for a reward. The present study used an alternative, more active measure of self-control performance, namely physical endurance. Third, we also considered the implications of increasing awareness of resistance-related sensations. This latter form of attention has not yet - to our knowledge-been investigated directly and experimentally. Therefore, in order to gain more insight in the influence of attentional control strategies, the present study concerned a direct comparison of the effect of focusing attention on versus focusing attention away from one's resistance-related sensations.

Based on previous observations (Karniol \& Miller, 1983; Mischel \& Ebbesen, 1970) as well as predictions made by the 2-system framework (Metcalfe \& Mischel, 1999) we anticipated that self-control performance would be facilitated when 
attention was directed away from the control-demanding action. In addition, findings from previous research (Karniol \& Miller, 1983; Yates \& Revelle, 1979) provided indirect evidence that when attention is paid to unpleasant sensations a decline of self-control is more likely to occur. Therefore, we expected that participants whose attention was directed towards self-control-inhibiting sensations, would perform worse compared to both participants who focus attention away from their regulatory efforts and control participants.

In order to test these predictions, we used an ego-depletion paradigm (Baumeister, Bratslavsky, Muraven, \& Tice, 1998) in which self-control performance has been shown to decrease when people exert self-control repeatedly. As a measure of selfcontrol we chose a physical exercise task, namely lifting a $1.5 \mathrm{~kg}$ weight as long as possible. Physical exercise tasks proved a successful measure of self-control in prior research (see, for example, Alberts et al., 2007; Ciarocco, Sommer, \& Baumeister, 2001, Study 2; Martijn et al., 2007; Muraven et al., 1998, Study 1). Because lifting a weight becomes fatiguing and even a little painful after a short period of time, the person feels the urge to stop lifting. Overcoming this fatigue and overriding the urge to quit requires self-control. We adopted the physical stamina measure as main dependent variable because it is a relatively inconspicuous measure for self-control; most people think that weight lifting primarily depends on muscular strength. Performance on the weight-lifting task was measured twice; at the beginning and at the end of the experiment. Differences in performance at the first and second physical stamina measure formed the main dependent variable.

One group of participants was instructed to pay close attention to the physical sensation in their arm while lifting the weight. In addition, they were presented with an anatomical drawing of an arm and were told which specific muscles and tendons are typically involved when a person lifts a weight. In this way, we ensured that during the self-control operation, attention was predominantly directed towards unpleasant, resistance-related sensations such as pain and fatigue. By focusing on these sensations people are likely to become highly aware of their desire to quit performing the demanding self-control task. In this case, the positive aspects related to quitting (e.g., relaxation) are comparable with "hot" reward properties.

Another group of participants was distracted by means of an intensive calculation task while they were lifting a weight. Since this calculation task strongly relied on working memory (maintaining and updating items in working memory) and was therefore cognitively demanding, participants' attention was expected to be mainly directed to this task and to a far lesser extent to the resistance-related sensations generated by the self-control task.

In order to compare performance of the two above mentioned groups, an additional group of participants performed the same sequence of physical selfcontrol as those in the two earlier described conditions but without being exposed to any attention manipulation. Finally, in order to isolate performance on the calculation task, yet another group of participants performed this task directly after the first physical self-control measurement. After performing the calculation task, these participants were asked to perform the second physical self-control measurement. In other words, instead of performing the calculations during the second self-control attempt, this group performed the calculation task before the second self-control task. As pointed out before, the calculation task strongly relied on working memory and should therefore require a certain amount of resources (Schmeichel, 2007). However, performing this memory task during or before a selfcontrol task should not make any difference, since the total amount of required 
resources is equal in both cases. Therefore, we expected no difference in performance for participants who performed the calculations during or before the second selfcontrol measurement.

\section{Method}

\section{Design and Participants}

Eighty first-year psychology students (60 men and 20 women, mean age $=20.5$ years, $S D=1.8$ ) of the Universiteit Maastricht received course credit for their voluntary participation. Men and women were randomly assigned to one of the four conditions: two experimental conditions in which type of focus (muscular sensations vs. distraction) was varied and two comparison or base-line control conditions (no instruction control and sequential task control). The experiment was approved by the standing ethical committee of our faculty.

\section{Procedure}

Participants were tested individually in 20-minute sessions. The experiment was presented as a study on mental and physical skills. The experimenter briefly explained the general procedure of the experiment after which participants signed a consent form. Next, participants were seated and asked to lift a $1.5 \mathrm{~kg}$ weight with their dominant arm. The experimenter started a chronometer at the moment the participant lifted the weight at a $90^{\circ}$ angle of the arm with the torso. The chronometer was stopped at the moment that a participant eased his or her arm and was not longer able to maintain the $90^{\circ}$ angle. After the first weight-lifting task, participant filled out a questionnaire that measured experienced fatigue and their mood. Next, type of focus was manipulated in the two experimental conditions. Participants in the muscular sensations condition were instructed to fully concentrate themselves on the arm and hand muscles that are involved when lifting a weight. To illustrate this, an anatomical illustration of an arm and hand was shown and the experimenter pointed at the muscles and tendons that are generally used to lift a weight. After this instruction, which lasted 3 minutes, participants lifted the weight again following the same procedure as in the first weight-lifting task.

Participants in the distraction condition received instructions about a cognitive calculation task that they were required to perform during the second weight-lifting task. This task was the Star Counting Task (SCT; De Jong \& Das-Smaal, 1990), which was designed to measure working memory capacity and requires the alternation of forward and backward counting. Each item in the SCT consists of a pattern of stars with plus signs, minus signs and empty spaces in between. The plus and minus signs specify the direction (adding or subtracting, respectively) in which the stars should be counted. Since the stars are presented in a table, empty spaces are added in order to prevent participants from counting multiple stars at once. Participants were instructed to start counting from a given number and sum the total number of stars. After completing each calculation, they had to indicate whether their answer matched or mismatched the number displayed at the top of each item. This number either represented the correct or an incorrect solution for the item concerned. Participants were asked to count aloud in order to make it possible for the experimenter to register the total number of stars counted. We used the SCT 
because its performance almost completely absorbs participants working memory and therefore leaves less capacity for other thoughts about physical self-control. Thus, the crucial difference between the two experimental conditions was that participants in the internal-focus condition were explicitly asked to concentrate themselves on their arm and hand muscles when lifting the weight whereas in the external-focus condition such thoughts were made impossible.

The third condition was added to furnish a baseline against which weight-lifting performance in the two experimental conditions could be compared. Participants in the no instruction control condition received no specific focus instructions and simply lifted the weight again with a 3-minute interval between the first and the second weight-lifting task. The fourth condition served as a baseline to compare the performance at the SCT. After the first weight-lifting task, participants in the sequential task control condition were given the SCT for 3 minutes and the number of calculations was registered. After performing the SCT, they lifted the weight for the second time. In all four conditions, the time interval between the first and the second weight-lifting task was the same ( $3 \mathrm{~min})$. Also, all participants used their same arm for both weight-lifting tasks.

After the second weight-lifting task, participants received two questionnaires to check their mood and their compliance with the instructions (manipulation check). Finally, participants were debriefed and thanked for their participation.

\section{Dependent Measures}

All questionnaire items were answered on 4-point Likert scales ranging from $1=$ totally disagree to $4=$ totally agree.

Mood. In order to check whether manipulations led to mood differences, participants completed the Brief Mood Introspection Scale (BMIS; Mayer \& Gaschke,1988) after the second weight-lifting task (Cronbach's $\alpha=.90$ ). The BMIS consists of 16 adjectives, tapping eight mood states (happy, loving, calm, energetic, anxious, angry, tired and sad) with 2 adjectives each. Participants were instructed to rate, "How well does each adjective or phrase describe your present mood".

Subjective fatigue. In order to measure subjective fatigue, participants indicated their agreement with 8 statements (I feel tired/energetic/fit/drowsy/dull/exhausted/I don't feel like doing anything/I have the feeling I can handle the world). Reliability of this scale was sufficiently high (Cronbach's $\alpha=.80$ ).

Star counting task. At the top of each item of the SCT, a number was presented that either represented the correct or an incorrect solution for the item concerned. Participants were asked to indicate whether their answer matched or did not match this solution. However, since participants did not always complete their last item and often stopped halfway though, we reasoned that determining performance by the number of correctly indicated matches or mismatches implied omission of information. Therefore, performance was solely determined by the total number of stars participants were able to count during weight-lifting time.

Manipulation check. Participants also completed one manipulation check question about what they were thinking about during the second physical measurement (During the physical task, I fully concentrated on my arm and hand). 
Physical performance. Using a stopwatch, the time (in $\mathrm{ms}$ ) that a participant lifted the weight was measured during both the first (baseline) and the second weightlifting period.

\section{Results}

Self-control performance was represented by the difference in weight-lifting time at the first and the second measurement. Five participants had deviant scores on the difference score of the two weight-lifting tasks $(z>2)$ and were recognized as outliers. ${ }^{1}$ Hence, analyses described below included the data of the remaining 75 participants.

\section{Manipulation Check}

Participants were asked to indicate what they were thinking of during the second physical measurement. Analysis revealed that participants in the muscular-sensations condition concentrated more on their hand and arm compared to the distraction condition, $t(37)=5.30, p<.001 \quad$ (two-tailed) $\quad\left(M_{\text {muscular-sensations condition }}=3.25\right.$, $\left.S D=0.85 ; M_{\text {distraction condition }}=1.89, S D=0.74\right)$. A similar pattern of results was found for the muscular-sensations condition versus the no instruction control condition, $t(36)=7.19, p<.01 \quad$ (two-tailed) $\left(M_{\mathrm{no}}\right.$ instruction control condition $=2.5$, $S D=0.79)$ and for the no instruction control condition versus the distraction condition, $t(35)=5.84, p=.02$ (two-tailed). In sum, these findings imply that our manipulations successfully directed participants' attention in the indicated direction.

An analysis of the fatigue and mood questionnaires revealed no significant differences among the four conditions, $F(3,71)=0.64, n s$, and $F(3,71)=0.84, n s$, respectively. This makes it unlikely that differences in physical self-control measurements between the four conditions can be attributed to a fatigue or mood effect.

\section{Physical Task Performance}

The one-way analysis of variance (ANOVA) with 4 cells showed that the scores on the first physical task did not differ by condition, $F(3,71)=0.83, \eta^{2}=.034$. For the analyses of a possible difference in the handgrip times at the first and second measurement, we used an ANOVA with the four conditions as independent variable, handgrip time 2 as dependent variable and handgrip time 1 as covariate. Performance on the first handgrip was a significant predictor of performance on the second handgrip, $F(1,70)=121.52, p<.001, \eta^{2}=.64$. Also, we found a significant effect of condition, $F(3,70)=15.10, p<.001, \eta^{2}=.40$. In order to further explore the effect of condition, a series of analyses was conducted in which we compared the specified conditions by using an ANOVA with the two involved conditions as independent variable, handgrip time 2 as dependent variable and handgrip time 1 as covariate. The first comparison revealed that participants in the distraction condition performed significantly better than participants in the muscular-sensations condition, $F(1,37)=23.37, p<.001, \eta^{2}=.39$. A second comparison showed that participants in the distraction condition outperformed participants in the no instruction control condition as well, $F(1,37)=23.37$, $p<.001, \eta^{2}=.39$. These findings imply that when participants were distracted by the 
difficult calculation task, they were able to perform better than participants who were asked to pay attention to their muscles while holding up the weight as well as participants who received no focus instruction. In addition, a comparison of the muscular sensations and no instruction control condition failed to reach significance, $F(1,36)=1.80, p=.19, \eta^{2}=.05$. In other words, participants who were instructed to focus their attention on their muscles while holding up the weight did not perform significantly worse than participants who did not receive this instruction.

Next, the impact of performing the calculation task before versus during the second physical measurement was investigated by comparing the distraction condition and the sequential task control condition. In contrast with our expectations, it was found that participants who performed the calculation task before the second physical measurement, performed significantly worse compared to those who performed the same task during the second measurement, $F(1$, $35)=18.10, p<.01, \eta^{2}=.35$. All means are summarized in Table 1 and show that participants in the distraction condition were able to keep their performance stable, while participants in the remaining conditions exhibited a decline in performance on the second physical measurement.

\section{Calculation Task}

In order to investigate whether stable self-control performance negatively interfered with performance on the calculation task, calculation task performance of participants in the distraction condition was compared to the performance of participants in the sequential task control condition. Participants in the sequential task control condition counted stars for a fixed period of time, namely three minutes. In the distraction condition, participants performed the task while lifting the weight. Since weight-lifting time varied among participants, the time they spent on solving calculations varied as well. Therefore, for participants in the distraction condition, we calculated the total number of stars they were expected to count in 3 minutes. For instance, the total numbers of stars of a participant who lifted the weight for one minute and counted 30 stars during this period of time, was $90(3 \times 30)$.

Subsequently, a one-way ANOVA was conducted in order to compare the expected number of calculations of participants in the distraction condition with the observed number of calculations of participants in the sequential task control

TABLE 1 Persistence (Means and Standard Deviations in Seconds) at the First and Second Weight-lifting task and the Difference Between the Two Weight-lifting tasks per Condition

\begin{tabular}{|c|c|c|c|}
\hline Condition & $\begin{array}{l}\text { Weight lift } \\
\text { test } 1 \\
M(S D)\end{array}$ & $\begin{array}{l}\text { Weight lift } \\
\text { test } 2 \\
M(S D)\end{array}$ & $\begin{array}{c}\text { Difference } \\
\text { (test } 2-\text { test } 1) \\
M(S D)\end{array}$ \\
\hline Distraction $(n=20)$ & $125(65)$ & $119(43)$ & $6(33)$ \\
\hline Muscular sensations $(n=19)$ & $104(45)$ & $77(23)$ & $-27(34)^{*}$ \\
\hline No instruction control $(n=20)$ & $101(54)$ & $68(28)$ & $-33(35)^{*}$ \\
\hline Sequential task control $(n=20)$ & $106(35)$ & $80(24)$ & $-26(26)^{*}$ \\
\hline
\end{tabular}

Note: Means with an asterisk indicate a significant difference $(p<.05)$ between the two weight-lifting tasks. 
condition. No significant difference was found, $F(1,35)=1.12$, $n s$. This finding suggests that relatively good self-control performance, as a result of an external focus strategy, did not negatively influence calculation task performance.

\section{Discussion}

The aim of the present research was to investigate the impact of attentional control strategies on self-control performance. Former delay of gratification studies have consistently demonstrated that children are better able to resist the temptation to eat from candy and wait for a larger reward when they focus attention away from the desirable food. The present investigation attempted to replicate and extend these findings by using an adult sample, a procedure that entailed active physical selfcontrol (rather than passive resistance) and by also addressing the implications of focusing attention on the self-control action. The latter allowed us to test the adequacy of ego depletion theory in the context of research on delay of gratification.

We hypothesized that self-control performance would increase when one focused attention away from the unpleasant, resistance-related sensations generated by the self-control task. Likewise, we expected that focusing on the resistance-related sensations would impair self-regulatory performance. In order to measure selfcontrol performance, participants were asked to complete a series of two identical physical self-control tasks.

According to the strength model, self-control requires energy and initial selfcontrol attempts should therefore hamper subsequent self-control performance. In line with this, the present results show that control participants, who received no focus instruction, showed a significant decline in performance on the second selfcontrol measurement. In contrast, participants who were distracted by a calculation task while performing the second self-control task, did not exhibit a significant decline in performance. Moreover, this group outperformed participants who focused their attention on their sensations of exertion while performing the physical self-control task. These findings suggest that the usage of attention strategies may help to circumvent the negative effects of ego depletion.

The current findings are compatible with the hot-cool system theory (Metcalfe \& Mischel, 1999). When people focus their attention on their muscles while exerting physical self-control, they may become highly aware of their desire to quit performing the exerting self-control task. In this case, the positive aspects related to quitting (e.g., relaxation) are comparable with "hot" reward properties. Since increased salience of tempting aspects associated with giving up is expected to cause activation of the hot system, self-control is more likely to fail. In contrast, by focusing attention away from the control-demanding action, thoughts about the hot reward properties associated with quitting are less salient, implicating less activation of the hot system.

Contrary to our expectations, it was found that the performance of people who focused their attention on the unpleasant sensations during the self-control task did not significantly differ from the performance of control participants who did not receive any focus instruction. This absence of differences might imply that directing attention internally, i.e., on the sensations of exertion, can be perceived as a default process or natural tendency that emerges when people exert self-control. In this case, the occurrence of ego depletion is partly mediated by ineffective or suboptimal attentional processes. Directing attention to one's regulatory efforts while exerting self-control may be a default process or natural tendency that emerges when people 
engage in self-regulatory efforts. Or, in terms of hot-cool system theory (Metcalfe \& Mischel, 1999), people may by default direct attention to "hot" reward properties. When this default attentional process is replaced by a process that is not primarily concerned with regulatory efforts, no negative influence on self-control performance seems to occur. Clearly, future research is needed to address this issue more directly.

We also found that performing the difficult calculation task before the second selfcontrol measurement resulted in a significant decrease in performance, whereas performing the task during the second self-control operation caused no significant decrease in self-regulatory performance. This finding is inconsistent with the strength model. This model would predict that performing the calculation task drains the same energy resource as performance on the physical self-control task. Moreover, in this view, exposure to the calculation task while exerting physical self-control should tax regulatory resources to the same extent as exposure to the calculation task before exerting physical self-control and should therefore affect regulatory performance similarly (see also Schmeichel, 2007). The current results prove otherwise by illustrating that regulatory performance is less negatively affected when the calculation task is performed during the physical measurement. In fact, more than that, a cognitively demanding task may be used as a way to overcome the decrease in performance that is associated with depletion of resources.

Also striking in this respect is the finding that participants who performed the calculation task during the physical self-control task did not show lower performance on the calculation task as compared to those who completed the task before the physical measurement. In other words, performing the physical selfcontrol task did not interfere negatively with performance on the calculation task. Although these findings can only be held as first evidence, they question the assumption of a general energy resource. It may be possible that performance on the physical self-control task relies on a different resource than the calculation task. In other words, although self-control may indeed rely on cognitive resources, the type of self-control may determine the resource that is drained by its use. Future research could test this proposition by varying both the self-control task that one has to perform as well as the type of task that one is distracted by.

Another possible explanation in terms of processes comes from the field of sport psychology. According to Wrisberg, Franks, Birdwell, and High: "an internal focus of attention during exercise increases cognizance of the fatigue element of bodily sensation present during exercise" (1988, p. 605). In the same way, a focus on the unpleasant sensations during self-control performance may increase cognizance of the effort present during self-control attempts. The awareness of one's efforts may initiate an inner dialogue (also referred to as an internal self-regulatory dialogue) that confronts the individual with the choice of keeping on or giving in (see Richards \& Gross, 2000). This inner dialogue is probably characterized by an "inner struggle" ("This is starting to hurt, I would really like to quit now. No I will not give in, I will try a little longer.").

In other words, beside the availability and taxation of cognitive resources, evaluative processes may also influence self-control performance. A task or activity that facilitates distraction from these processes may help to improve self-control performance. The extent to which this distraction relies on cognitive resources may be subordinate to the potential of this distraction to circumvent the inner dialogue and the evaluative processes that accompany this dialogue.

In this view, the occurrence of ego depletion (at least partly) reflects the interpretation of ones regulatory efforts. Indirect support for this rationale was 
provided by Vohs and Schmeichel (2003), who showed that participants who took part in a self-control demanding task, as compared to a control group, systematically overestimated the duration of that task. This belief may result in abandonment of further self-control. This points to the fact that subsequent self-control efforts are, at least in part, guided by subjective interpretations of prior efforts and not by the "objective" amount of energy invested per se. Interpretation of self-control efforts may constitute an important process that contributes to self-control failure: these efforts may be used to justify one's decision to give in to impulses or desires. In other words, the fact that people become aware of their effort investment during selfcontrol may function as a "legitimate" reason to quit future self-control attempts. Distraction may help to reduce cognizance of one's regulatory efforts, thereby circumventing the occurrence of ego depletion.

In short, this evidence contributes both to the literature on ego depletion theory and to that on delay of gratification by showing that the usage of attentional strategies can help to improve regulatory performance and overcome the occurrence of ego depletion, and suggesting that the benefits of employing these strategies are not restricted to children but apply to adults as well.

\section{Note}

1. Including the five outliers in the analysis did not lead to a different pattern of results.

\section{References}

Alberts, H. J. E. M., Martijn, C., Greb, J., Merckelbach, H., \& De Vries, N. K. (2007). Carrying on or giving in: The role of automatic processes in overcoming ego depletion. British Journal of Social Psychology, 46, 383-399.

Baumeister, R. F., Bratslavsky, E., Muraven, M., \& Tice, D. M. (1998). Ego depletion: Is the active self a limited resource? Journal of Personality and Social Psychology, 74, $1252-$ 1265.

Ciarocco, N. J., Sommer, K. L., \& Baumeister, R. F. (2001). Ostracism and ego depletion: The strains of silence. Personality and Social Psychology Bulletin, 27, 1156-1163.

De Jong, P. F., \& Das-Smaal, E. A. (1990). The Star Counting Test: An attention test for children. Personality and Individual Differences, 11, 597-604.

Karniol, R., \& Miller, D. T. (1983). Why not wait? A cognitive model of self-imposed delay termination. Journal of Personality and Social Psychology, 45, 935-942.

Martijn, C., Alberts, H. J. E. M., Merckelbach, H., Havermans, R., Huijts, A., \& de Vries, N. K. (2007). Overcoming ego depletion: The influence of exemplar priming on self-control performance. European Journal of Social Psychology, 37, 231-238.

Mayer, J. D., \& Gaschke, Y. N. (1988). The experience and meta-experience of mood. Journal of Personality and Social Psychology, 55, 102-111.

Metcalfe, J., \& Mischel, W. (1999). A hot/cool-system analysis of delay of gratification: Dynamics of will-power. Psychological Review, 106, 3-19.

Mischel, W., \& Ebbesen, E. B. (1970). Attention in delay of gratification. Journal of Personality and Social Psychology, 16, 329-337.

Mischel, W., Ebbesen, E. W., \& Zeiss, A. R. (1972). Cognitive and attentional mechanisms in delay of gratification. Journal of Personality and Social Psychology, 21, 204-218.

Muraven, M., \& Baumeister, R. F. (2000). Self-regulation and depletion of limited resources: Does self-control resemble a muscle? Psychological Bulletin, 126, 247-259.

Muraven, M., \& Slessareva, E. (2003). Mechanism of self-control failure: Motivation and limited resources. Personality and Social Psychology Bulletin, 29, 894-906. 
Muraven, M., Tice, D. M., \& Baumeister, R. F. (1998). Self-control as limited resource: Regulatory depletion patterns. Journal of Experimental and Social Psychology, 74, $774-$ 789.

Richards, J. M., \& Gross, J. J. (2000). Emotion regulation and memory: The cognitive costs of keeping one's cool. Journal of Personality and Social Psychology, 79, 410-424.

Rodriguez, M. L., Mischel, W., \& Shoda, Y. (1989). Cognitive person variables in the delay of gratification of older children at risk. Journal of Personality and Social Psychology, 57, $358-367$.

Schmeichel, B. J. (2007). Attention control, memory updating, and emotion regulation temporarily reduce the capacity for executive control. Journal of Experimental Psychology: General, 136, 241-255.

Schmeichel, B. J., \& Baumeister, R. F. (2004). Self-regulatory strength. In R. F. Baumeister \& K.D. Vohs (Eds.), Handbook of self-regulation: Research, theory, and applications (pp. 84-98). New York: Guilford Press.

Strack, F., \& Deutsch, R. (2004). Reflective and impulsive determinants of social behavior. Personality and Social Psychology Review, 8, 220-247.

Vohs, K. D., \& Schmeichel, B. J. (2003). Self-regulation and the extended now: Controlling the self alters the subjective experience of time. Journal of Personality and Social Psychology, 83, 217-230.

Wrisberg, C. A., Franks, B. D., Birdwell, M. W., \& High, D. M. (1998). Physiological and psychological responses to exercise with an induced attentional focus. Perceptual and Motor Skills, 66(2), 603-616.

Yates, J. F., \& Revelle, G. L. (1979). Processes operative during delay of gratification. Motivation and Emotion, 3, 103-115. 